\title{
Analysis of NQI technology integration and application status of building sanitary ceramics industry
}

\author{
Tan Yibing ${ }^{1}$ \\ ${ }^{1}$ Quality and Technical Supervision and Inspection Center of Xuchang (National Quality Supervision and Inspection \\ Center for Ceramic Products of China (Henan)),Xuchang, Henan China
}

\begin{abstract}
Based on the National Quality (National Quality Infrastructure, NQI) theoretical connotation as the instruction, this paper analyzes the domestic building sanitary ceramics industry key generic NQI technology integration and application of the status quo, the results show that the current domestic building sanitary ceramics industry NQI key generic technology integration and application level is not high, it is difficult to meet the demand of industry transformation and upgrading of the green, in urgent need of research to support green building sanitary ceramics industry upgrade of key generic NQI technology,to form a scientific and rational green building sanitary ceramics key testing equipment measuring standard, high quality green building sanitary ceramics standards, certification evaluation standard, and green standards in key areas (energy saving, water saving, low carbon), implementation contains measuring, testing, standards, certification and accreditation whole chain NQI technology system and carry out application demonstration, to accelerate the transformation and upgrading of domestic green building sanitary ceramics industry form the standard support and high quality development.
\end{abstract}

\section{Introduction}

The National Quality Foundation (NQI) [1] is composed of measurement, standards, and conformity assessment (inspection, testing, and certification and accreditation) [2]-[3]. NQI is recognized internationally as the cornerstone of improving quality competitiveness and protecting the national economy. Technical rules for orderly operation, an important technology platform to promote scientific and technological innovation, and an important technical means to enhance international competitiveness. In China, as the state and local governments gradually increase their investment in NQI, more and more scholars have begun to pay attention to and study NQI and continue to deepen and improve, especially in the development history, concept, connotation, mechanism and There have been more systematic studies on the impact. The National Quality Foundation (NQI) framework diagrams studied by foreign scholars and Chinese scholars are shown in Figure 1, respectively.

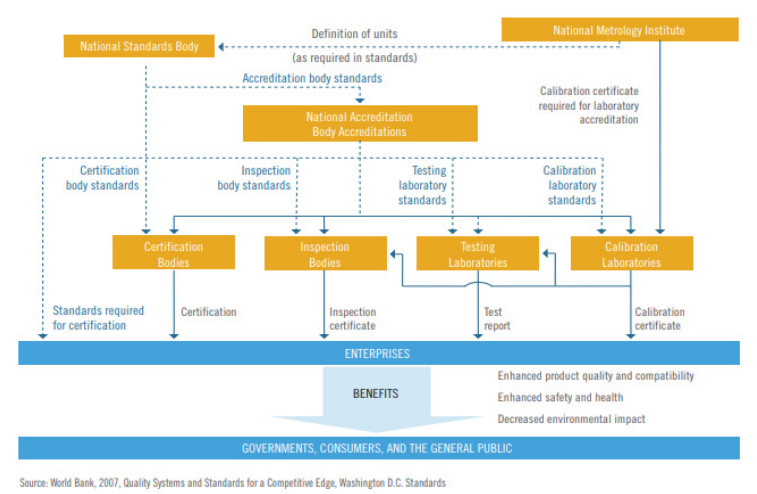

Figure 1 The national quality infrastrucutre

However, all researches at home and abroad are mainly focused on the national quality foundation itself. In the specific industry as the research object, there is insufficient research in the field of NQI's promotion of industry and quality promotion, such as the building and sanitary ceramic industry. At present, China has developed into the world's largest manufacturer of building and sanitary ceramics. According to statistics, from January to December 2019, 362 sanitary ceramic companies above designated size achieved revenue of 79.772 billion yuan, and the output of sanitary ceramics exceeded 237 million pieces. From January to December 2019 , the main business income of the building ceramic industry above designated size was 307.99 billion yuan, and the national ceramic tile output was 10.161 billion 
square meters. Therefore, this article takes the building and sanitary ceramics industry as the specific research object, and conducts research and analysis on the integration and application status of key common NQI technologies in the industry.

\section{Status of integration and application of key common NQI technologies}

At present, the quality foundation of domestic building sanitary ceramics is weak, mainly in the following aspects:

-Measurement field: The research and application of measurement technology for the key testing equipment of green building sanitary ceramics is seriously insufficient, such as the measurement standard for the whole building sanitary ceramics testing equipment. At present, there are corresponding verification procedures for the individual components of the building and sanitary ceramic testing equipment, but the verification procedures for the entire test device are missing. The building and sanitary ceramics testing equipment is a non-standard testing device. When the key components of the equipment meet the corresponding verification regulations, the equipment pipeline structure and the layout of the test instruments are different, which will have a significant impact on the experimental results. As a result, when the equipment of each laboratory is qualified for the components, the data issued by each laboratory equipment is quite different, which directly affects the results of product supervision and random inspection, making laboratory data inconsistent and incomparable, causing relevant government quality supervision departments and quality Inspection agencies and production companies are at a loss;

Standard areas: The research and application of key standards related to green building sanitary ceramics are seriously insufficient, such as green design standards and energy-saving supervision standards. With the continuous tightening of environmental protection policies and increasingly intensified market competition, the sanitary ceramics industry is facing unprecedented pressure for survival. The important path to eliminate or alleviate the survival pressure of enterprises is industrial transformation and upgrading. The important prerequisite for achieving industrial green upgrading is to have a system Sexual green design thinking. Systematic green design thinking is a major issue. Currently, there are no relevant standards for the green design of sanitary ceramics at home and abroad. The green design and development of corporate products only considers a single green factor, such as water saving, light weight, energy saving, emission reduction, and recycling, and lacks systematic green design thinking. The building and sanitary ceramics industry is a traditional energy-intensive consumer. One of the important measures to promote the green transformation and upgrading of the building and sanitary ceramics industry is enterprise energy conservation, emission reduction, and clean production. Only through supervision can enterprise energy conservation work be reflected, sustained and long-term. However, at present, the lack of relevant standards for energy-saving supervision in the building and sanitary ceramics industry, the insufficient supervision system, the inconsistent methods and methods, the inadequate standardization of procedures, and the uneven level of personnel skills have largely restricted the impact of energy-saving supervision on the industry Effective play of the supporting role of the green upgrade;

Certification field: The research and application of key common certification technologies in the green building sanitary ceramics industry are seriously insufficient, such as water-saving and energy-saving certifications. The two key elements of the green transformation and upgrading of the building and sanitary ceramics industry are energy saving and water saving. However, the current research work related to such certification is insufficient, the certification coverage rate is insufficient, and the degree of social recognition is not high. As a typical high-energy-consuming industrial equipment, ceramic industry kilns account for about $60 \%$ of the energy consumption of ceramic industry production. However, at present, there is no technical evaluation system standard for energy-saving certification of ceramic kilns at home and abroad. Another example is that the ceramic industry is a typical industry that consumes a lot of water resources. It is of great practical significance to study the water footprint quantification, evaluation and certification methods and common key technologies of ceramic products. However, there is currently no ceramic product-related water at home and abroad. Footprint certification technology evaluation system standards;

The building and sanitary ceramic industry is a typical high-energy, high-polluting traditional manufacturing industry. It is currently facing the dual pressures of the market and environmental protection. It is in urgent need of green transformation and upgrading. One of the key paths for transformation and upgrading is in the green upgrade of the building and sanitary ceramic industry. Carry out the NQI technology integration and application pilot, that is, first carry out the NQI technology integration and application demonstration of measurement, standard, inspection and certification, and promote the green upgrade of the industry in the building and sanitary ceramics industry. At the same time, explore the effect of NQI technology on the high-quality development of traditional industries. The good demonstration effect provides a reference for other traditional manufacturing industries to achieve green development through NQI construction.

\section{Conclusion}

The above analysis shows that the integration and application of key generic technologies of NQI in the domestic building sanitary ceramics industry is not high,which is difficult to meet the demand of green transformation and upgrading of the industry. 
Therefore, it is urgent to study the key generic technologies of NQI that support the green upgrading of the building sanitary ceramics industry.Strengthening the generic technology research and application of the quality foundation of the traditional domestic manufacturing industry has important practical significance for promoting the green upgrading of the domestic industry, maintaining the medium-high speed and sustained growth of economic development, and moving towards the medium-high level.In the future, there will be more NQI construction in specific industries, standard setting in emerging industries and Chinese standard going global.

\section{References}

1. Department of Science and Technology, AQSIQ. NQI: Consolidate the quality of the country strategy to lead the economic and social development [J]. Quality and Certification, 2016(4): 28-30.

2. UNIDO. Quality Infrastructure[R], 2006.

3. World Bank. The National Quality Infrastructure [R], 2013. 